\title{
Test To Physical Condition Parameters: For The Football Athletes Persik Kediri Under - 20 At 2020
}

\author{
Nur Ahmad Muharram1, Slamet Junaidi², Sugito ${ }^{3}$, M. Anis Zawawi, ${ }^{4}$, M. Akbar Husein Allsabah ${ }^{5}$ \\ 1, 2, 3, 4, 5 Nusantara University PGRI Kediri \\ Email: 1nur.ahmad1988@unpkediri.ac.id, 2slamet.junaidi@unpkediri.ac.id, ${ }^{3}$ Sugito@unpkediri.ac.id, \\ 4zawawi@unpkediri.ac.id, ${ }^{5}$ Akbarhusein@unpkediri.ac.id \\ doi https://doi.org/10.36526/gandrung.v1i2.915
}

\begin{abstract}
The purpose of this parameter test is to equip persik trainers with themselves and their staff in order to know the physical condition of the U-20 persik kediri athlete so that the training program can be on target. In addition, the parameter test is also used to evaluate the progress of training towards achievement in each match. This parameter test also has the benefit of setting methods for preparing parameter tests and compiling test guidelines, or SOP so that parameter tests carried out in the field have valid and reliable test prerequisites, and have the same interpretation throughout Indonesia, especially in the Football Sports Branch. For the method here, it uses the field practice method through the persik kediri athlete U-20 to carry out a series of parameter tests in soccer Athletes are asked to carry out the test series in accordance with SOPs that have been determined. The results of this parameter test are that the persik kediri athlete U-20 has physical conditions in categories or good norms in each form of test that is directed at the physical condition of soccer athletes
\end{abstract}

Keyword: parameter test, football, persik

\section{Pendahuluan}

Sepakbola adalah suatu permainan yang dilakukan dengan jalan menyepak, yang mempunyai tujuan untuk memasukkan bola ke gawang lawan dengan mempertahankan gawang tersebut agar tidak kemasukan bola. Menurut Hapsari dan Wibowo (2015), Olahraga sepak bola merupakan olahraga yang populer di dunia, begitu pula di Indonesia, olah raga ini bisa dibilang adalah primadonanya olahraga Indonesia. Sejalan dengan pendapat tersebut menunjukkan bahwa tugas seorang pemain sepakbola yaitu harus mampu melakukan teknik dengan bola dan teknik tanpa bola dengan baik yang bertujuan untuk dapat mencetak gol sebanyak mungkin di gawang lawan dan menjaga gawang dari kebobolan. Tujuan utama dalam permainan sepakbola ini yang menjadikan pemain sepakbola secara kolektif harus mampu memiliki skill, mental dan kondisi fisik secara prima agar dapat bermain dalam tim dengan baik. Pola pergerakan sepakbola yang berat dan lebih sering mendapatkan gangguan dari lawan ini yang akan mempengaruhi kualitas permainan pemain tersebut (Muhajir, 2004: 22). Sedangkan menurut Muharram NA, dkk, Pengembangan motorik kasar sama pentingnya dengan aspek-aspek perkembangan lainnya, karena ketidakmampuan siswa melakukan kegiatan fisik akan membuat siswa kurang percaya diri, bahkan menimbulkan konsep diri negatif dalam kegiatan fisik.

Volume 1, Number 2, Juli 2020 | 13 
GANDRUNG: Jurnal Pengabdian Kepada Masyarakat ISSN: 2721-6136 (Online)

Bermain sepakbola tidak cukup hanya dengan memiliki skill yang baik saja tetapi membutuhkan dukungan secara menyeluruh agar dapat bermain dengan baik. Menurut Pratama B.A. (2015), "Dalam bermain sepakbola, pemain dituntut untuk selalu bergerak. Gerak yang dilakukan menggiring bola, untuk melakukan gerakan tersebut diperlukan kondisi fisik tinggi". Kondisi fisik adalah salah satu prasyarat yang sangat diperlukan dalam usaha peningkatan prestasi seorang atlet, bahkan sebagai landasan titik tolak suatu awalan olahraga prestasi. Raihan prestasi yang tinggi seorang atlet dan tim sepakbola akan tergantung terhadap kemampuan dan kondisi fisik yang dimiliki. Hal ini menunjukkan bahwa kondisi fisik akan menjadi faktor yang berpengaruh besar terhadap prestasi atlet. Program latihan yang teratur dan terkontrol dengan baik akan mampu meningkatkan kemampuan dan kondisi fisik pemain untuk dapat menampilkan kemampuan bermainnya dengan maksimal (Sajoto, 1999: 13). Menurut Muharram NA (2015), Penggunaan strategi pembelajaran yang efektif dan efisien akan sangat membantu pencapaian pengalaman belajar siswa atau atlet.

Menurut Muharram (2015), "Kemajuan dibidang ilmu pengetahuan dan teknologi jelas berdampak luas dalam perkembangan teori dan metodologi pelatihan. Persiapan yang matang serta program latihan yang disusun secara sistematis mutlak diperlukan. Banyak hambatan yang selama ini sering dihadapi beberapa diantaranya waktu pemusatan latihan yang pendek, hanya beberapa bulan saja. Pendeknya jangka waktu latihan jelas akan berdampak pada pencapaian peak performance yang kurang optimal, sehingga berakibat hasil prestasi yang dicapai tidak bisa maksimal pula. Padahal tujuan utama pemain berlatih adalah untuk mencapai prestasi puncak (peak perfomance) pada pertandingan utama saat digelarnya sebuah kompetisi. Untuk itu pembinaan pemain harus direncanakan dengan baik dan benar dan didasarkan pada konsep periodisasi dan prinsip-prinsip latihan serta metodologi penerapannya di lapangan. Masalah yang paling kompleks dan menantang dalam metodologi latihan adalah bagaimana mencapai peak performance pada tanggal dan waktu yang telah direncanakan. Peak perfomance tidak dicapai secara kebetulan. Terciptanya peak perfomance adalah hasil dari persiapan atlet yang amat cermat, berdasarkan program latihan yang terorganisasi secara rinci, direncanakan secara bertahap, obyektif dan diterapkan secara berkesinambungan. Peak perfomance adalah hasil langsung dari adaptasi atlet terhadap berbagai sistem, metode, dan bentuk latihan. Perencanaaan yang matang akan berakibat pada degree of training dan kualitas latihan akan naik sehingga akan meningkatkan pula kapasitas kerja atlet serta ketrampilannya. Kalau training disusun secara subyektif, pelatih hanya mengandalkan pada instinct atau feeling saja, maka hasil peak perfomance biasanya juga hanya kebetulan saja. Seringkali peak perfomance dicapai sebelum pertandingan utama. Sebaliknya, sering pula peak perfomance dicapai sesudah pertandingan utama selesai. Dalam upaya menyusun program latihan untuk meningkatkan prestasi harus memperhatikan empat aspek (1) aspek fisik, (2) teknik, (3) 
GANDRUNG: Jurnal Pengabdian Kepada Masyarakat ISSN: 2721-6136 (Online)

taktik serta (4) aspek mental. Keempat aspek tersebut harus dilatih dengan cara dan metode yang benar agar setiap aspek dapat berkembang secara maksimal. Penelitian ini dikhususkan hanya mengenai aspek fisik karena jika kita mengkaji semua aspek dalam latihan maka akan sangat luas cakupannya, sehingga peneliti hanya membatasi pada permasalahan fisik saja. Mengapa demikian? Aspek fisik merupakan yang utama karena sangat dominan dan sangat mempengarui terhadap kualitas aspekaspek yang lain. Aspek teknik, taktik serta mental tidak akan bisa berkembang tanpa dukungan fisik yang prima. Sehingga aspek fisik merupakan komponen yang sangat mendasar untuk menentukan kemampuan seorang pemain dapat menyelesaikan suatu program latihan, maupun kondisi yang prima dalam suatu pertandingan".

Menurut Puspodari dan Muharram NA (2018), "Atlet yang memiliki kondisi fisik yang baik, akan lebih cepat pula menguasai teknik-teknik gerakan yang dilatih. Karena latihan teknik, taktik, dan keterampilan akan mampu dilakukan secara maksimal, artinya meskipun harus mengulang suatu gerakan atau suatu pola taktik tertentu berpuluh kali, dia tidak akan cepat lelah". Parameter dalam cabor sepakbola sangat diperlukan oleh seorang pelatih. Dalam kegiatan melatih seorang pelatih harus mempunyai parameter yang tepat untuk atlet. Artinya apabila parameter itu tidak tepat, maka pelatih tidak bisa mengetahui kemampuan atlet sehingga dalam pembuatan perencanaan progam latihan pun tidak sesuai. Menurut Kamus Besar Bahasa Indonesia (KBBI) yang dimaksud dengan parameter adalah ukuran seluruh populasi dalam penelitian yang harus diperkirakan dari yang terdapat dalam percontohan. Parameter merupakan sebuah nilai yang mengikuti sebagai acuan, keterangan atau informasi yang dapat menjelaskan batas-batas atau bagian-bagian tertentu dari suatu sistem. Parameter mengandung pengertian yaitu indikator dari suatu distribusi hasil pengukuran. Parameter juga berarti suatu nilai yang menggambarkan karakteristik suatu populasi, dikutip dari http://www. docs-finder.com/pengertianparameter-doc2.html.

Suatu tes pengukuran sangat dibutuhkan oleh siapa saja yang memerlukan data atau informasi mengenai individu atau kelompok. Menurut Allen Philips (1979: 1-9), a test is commonly difined as a tool or instrument of measurement that is used to obtain data about a specific trait or 9 characteristic of an individual or group. (Tes biasanya diartikan sebagai alat atau instrumen dari pengukuran yang digunakan untuk memperoleh data tentang suatu karakteristik atau ciri yang spesifik dari individu atau kelompok) dikutip dari http://sindemeysin.blogspot.com /2020/05/pengertiantes-pengukuran-eveluari-dan.html.

Menurut Burhan (2010: 7) tes merupakan sebuah instrumen atau prosedur yang sistematis untuk mengukur suatu sampel tingkah laku, misalnya untuk menjawab pertanyaan "seberapa baik (tinggi) kinerja seseorang yang jawabnya berupa angka. Selain itu tes juga dapat dikatakan sebagai prosedur yang sitematis guna mengobservasi dan memberi deskripsi sejumlah atau lebih ciri seseorang dengan

Volume 1, Number 2, Juli 2020 | 15 
bantuan skala numerik atau suatu sistem kategoris. Dengan demikian tes merupakan prosedur yang sistematis untuk memperoleh data dari individu atau kelompok, adapun fungsi dari adanya tes adalah untuk mengetahui kemampuan atau keterampilan, menyiapkan dasar untuk mencapai kemajuan, mendiagnosis kelemahan, dan meramalkan kemungkinan di masa depan.

Secara umum tujuan dari tes parameter ini adalah untuk membekali para pelatih dalam menciptakan dan menggunakan tes parameter untuk para atlet khusus nya atlet sepakbola dalam rangka melakukan evaluasi perkembangan latihan menuju prestasi dalam pertandingan yang diikutinya.

\section{Metode}

Metode yang digunakan dalam tes parameter ini adalah survei dengan teknik pengumpulan data menggunakan tes dan pengukuran. Dengan jumlah atlet 27 atlet. Tahapan dalam persiapan dan juga pelaksanaan tes parameter atlet PERSIK U-20 yaitu medicine ball, vertical jump, tinggi badan, flexibility, kelincahan, koordinasi mata tangan, koordinasi mata kaki, MFT. Semua yang dipersiapkan dilaksanakan dengan SOP(Standart Operasional Prosedur). Penelitian ini bertujuan untuk mengetahui profil kondisi fisik atlet sepakbola persik kediri U-20.

\section{Hasil dan Diskusi}

Tabel 1. Kategori hasil tes parameter atlet persik kediri U-20

\begin{tabular}{ccccc}
\hline No & Interval & Frekuensi & Presentase (\%) & Kategori \\
\hline $\mathbf{1 .}$ & $47-55$ & 0 & 0 & Baik Sekali \\
\hline $\mathbf{2 .}$ & $38-46$ & 17 & $63 \%$ & Baik \\
\hline 3. & $29-37$ & 10 & $37 \%$ & Sedang \\
\hline $\mathbf{4}$ & $20-28$ & 0 & 0 & Kurang \\
\hline $\mathbf{5 .}$ & $11-19$ & 0 & 0 & Kurang sekali \\
\hline $\mathbf{6 .}$ & Jumlah & 27 & $100 \%$ & \\
\hline
\end{tabular}

Dari di atas dapat disimpulkan bahwa profil kondisi fisik pemain sepakbola Persik Kediri U-20 adalah Baik, dengan pertimbangan frekuensi terbanyak berapa pada kategori Baik dengan 17 atlet atau dalam prosentase $63 \%$, sedangkan atlet dalam kategori Sedang dengan frekuensi sejumlah 10 atlet atau dalam prosentase $37 \%$. 
GANDRUNG: Jurnal Pengabdian Kepada Masyarakat ISSN: 2721-6136 (Online)

Tabel 2. Hasil tes Parameter Atlet PERSIK Kediri U-20

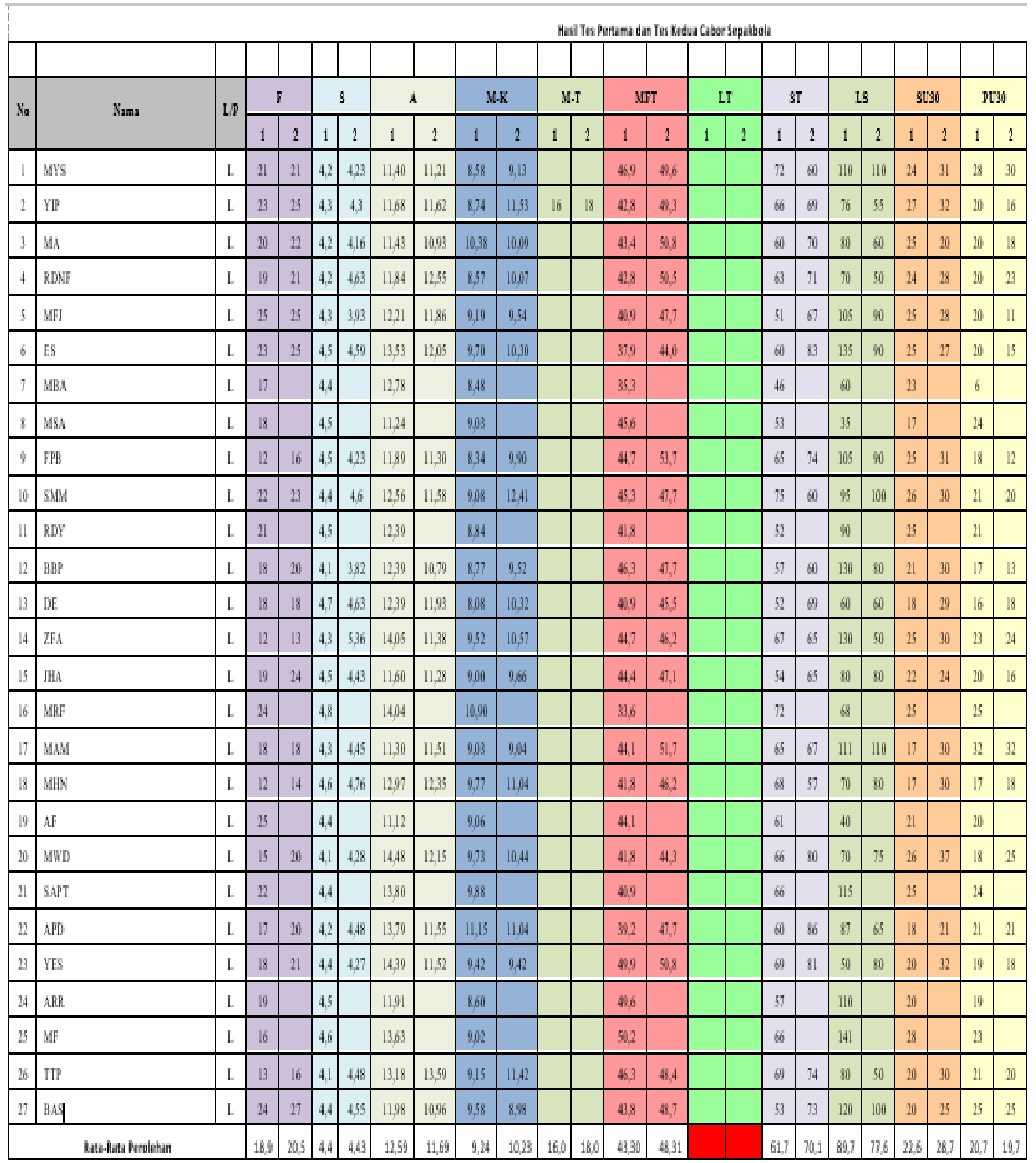


GANDRUNG: Jurnal Pengabdian Kepada Masyarakat ISSN: 2721-6136 (Online)

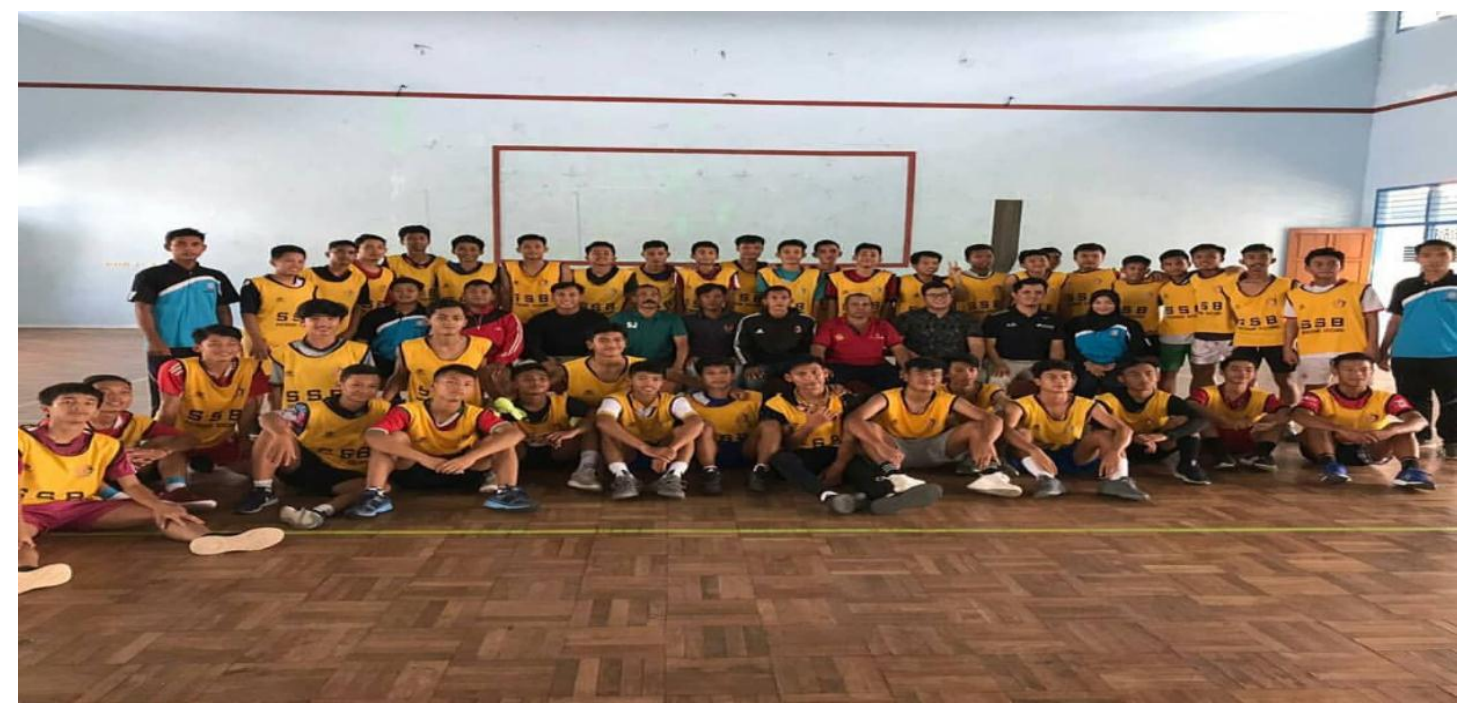

Gambar 1. Atlet PERSIK Kediri U-20 di GOR Kampus 4 UNP Kediri

\section{Kesimpulan}

Berdasarkan hasil tes parameter atlet sepakbola persik kediri U-20 yang sudah dilaksanakan diambil kesimpulan bahwa kondisi fisik atlet persik U-20 mempunyai kategori frekuensi yang Baik, dimana ini nantinya bisa dijadikan acuan oleh pelatih untuk memberikan program latihan dengan tepat sehingga nantinya kondisi fisik atlet tersebut bisa sesuai dengan program latihan yang diterapkan oleh jajaran pelatih persik kediri U-20.

\section{Daftar Referensi}

Allen, Mary J dan Wendy M. Yen. 1979. "Introduction to Measurement Theory". Monterey, CA: Brooks/Cole Publishing Company.

Bungin, B. 2010. Metodologi Penelitian Kualitatif. PT. Raja Grafindo Persada. Jakarta.

Hapsari dan Wibowo, (2015). Fanatisme dan Agresivitas Suporter Klub Sepak Bola. Jurnal Psikologi, 8(1), 52-58. https://ejournal.gunadarma.ac.id/index.php/psiko/article/view/1291

$\mathrm{Http}: / / w w w . d o c s-f i n d e r . c o m / p e n g e r t i a n-p a r a m e t e r-d o c 2 . h t m / / 06 / 2020$

Http://sindemeysin.blogspot.com /2020/05/pengertiantes-pengukuran-eveluari-dan.html.

Sajoto, M. 1988. Pembinaan Kondisi Fisik dalam Olahraga. Jakarta: DEPDIKBUD.

Muhajir. (2014). Pendidikan Jasmani Teori dan Praktik. Jakarta. Erlangga.

Muharram, NA. 2016. "Evaluasi Program Latihan Fisik Sepakbola Menggunakan Metode CIPP". Jurnal

Efektor vol. 3 No.1: 36-44. https://ojs.unpkediri.ac.id/index.php/efektor-e/article/view/204

Muharram, NA dkk. 2020. "Implementation of SECAR (Senam Ceria) Through Aerobic Kids in Elementary

School Laboratory Nusantara PGRI Kediri University". Jurnal Pengabdian Kepada Masyarakat Vol.1 No.1 : 18-22. https://ejournal.unibabwi.ac.id/index.php/gandrung/article/view/850

Muharram, N. A. 2015. "Pengaruh Pembelajaran dan Kemampuan Gerak Dasar Terhadap Peningkatan Kemampuan Sprint 100 Meter". Jurnal SPORTIF : Jurnal Penelitian Pembelajaran,1(1), 22-31. https://doi.org/10.29407/js_unpgri.v1i1.572 
GANDRUNG: Jurnal Pengabdian Kepada Masyarakat ISSN: 2721-6136 (Online)

Puspodari, P., \& Muharram, N. A. 2018. "Evaluasi Tingkat VO2Max Atlet Taekwondo Pemusatan Latihan Atlet Kota (PUSLATKOT) Kediri Tahun 2018". Prosiding Seminar Nasional IPTEK Olahraga (SENALOG), $\quad 1(1), \quad$ IKOR 11-15. Retrieved from https://ejournal.unibabwi.ac.id/index.php/semnassenalog/article/view/181

Pratama, B. A. 2015. Kontribusi Kecepatan dan Kelentukan Terhadap Hasil Menggiring Bola: Studi Pada Ekstrakurikuler Sepakbola Di SMK Pemuda Papar. Jurnal SPORTIF : Jurnal Penelitian Pembelajaran,1(1), 74-80. https://doi.org/10.29407/js_unpgri.v1i1.576

William, E. H. 2011. Motor Learning And Control : From Theory to Practice. California: Wadsworth. Zidane, A.H. M. 2013. Menjadi pemain sepakbola profesional. Kata Pena. 